\title{
Affective temperaments in nicotine-dependent and non-nicotine-dependent individuals
}

\author{
Wtodzimierz Oniszczenko ${ }^{1 \cdot A, B, C, D, E, F, G}$, Ewa Stanistawiak ${ }^{2 \cdot B, D, E, F}$ \\ 1: Faculty of Psychology, University of Warsaw, Warsaw, Poland \\ 2: Faculty of Psychology, University of Finance and Management, Warsaw, Poland
}

BACKGROUND

One of the smoking risk factors influencing nicotine dependency may be human personality; however, few studies have examined the association between Akiskal's affective temperaments and smoking in adults. Our study aims to evaluate the associations between nicotine dependence and affective temperaments using the TEMPS-A.

\section{PARTICIPANTS AND PROCEDURE}

The sample in this study consisted of 678 healthy Caucasian adults aged from 17 to 69 years, including 134 self-declared nicotine-dependent subjects (89 females and 45 males) and 544 self-declared non-nicotine-dependent subjects (352 females and 192 males). The Polish version of the Temperament Evaluation of Memphis, Pisa, Paris and San Diego Autoquestionnaire (TEMPS-A) was used to assess affective temperaments (depressive, cyclothymic, hyperthymic, irritable and anxious).
RESULTS

Nicotine-dependent individuals scored higher on cyclothymic, irritable and anxious temperaments than non-nicotine-dependents (no significant differences with regard to depressive and hyperthymic temperaments). Among the nicotine-dependent individuals, females scored higher on anxious temperaments than males (no differences with regard to the other affective temperaments), and among the non-nicotine-dependent individuals, females exhibited more depressive, cyclothymic and anxious temperaments than males, while males exhibited more hyperthymic temperaments than females.

\section{CONCLUSIONS}

The results suggest that affective, cyclothymic and irritable temperaments in both genders and anxious temperaments in females may be predictors of nicotine dependence in adults.

KEY WORDS

affective temperaments; nicotine dependence; adults

CORRESPONDING AUTHOR - Prof. Włodzimierz Oniszczenko, Faculty of Psychology, University of Warsaw, 5-7 Stawki Str., 00-183 Warsaw, Poland, e-mail: wlodek@psych.uw.edu.pl

Authors' Contribution - A: Study design · B: Data collection · C: Statistical analysis · D: Data interpretation ·

E: Manuscript preparation · F: Literature search · G: Funds collection

TO CITE THIS ARTICLE - Oniszczenko, W., \& Stanisławiak, E. (2016). Affective temperaments in nicotine-dependent

and non-nicotine-dependent individuals. Current Issues in Personality Psychology, 4(3), 125-131.

RECEIVED 24.04.2016 · REVIEWED 24.06.2016 · ACCEPTED 26.06.2016 · PUBLISHED 25.07.2016 


\section{BACKGROUND}

Smoking causes severe health impairment and death. Personality may be one of the factors influencing nicotine dependency.

In a meta-analysis, Munafó, Zetteler and Clark (2007) revealed that increased extraversion and increased neuroticism (derived from Eysenck's theory of personality) are associated with an increased likelihood of smoking. Hakulinen et al. (2015) confirmed, in a meta-analysis, that current smoking is associated with higher extraversion, higher neuroticism and lower conscientiousness. According to McChargue, Cohen and Werth-Cook (2004), positive and negative moods may predict cigarette dependence, and neuroticism partially mediates the relationship between positive mood and cigarette dependence. Cheng and Furnham (2016) showed that extraversion, conscientiousness and openness, three of the Big Five personality traits, were significant predictors of current smoking status in adults (user or non-user). However, Kleinjan et al. (2012) showed that neuroticism and extraversion did not independently predict nicotine dependence, while exposure to smoking in the social environment posed a risk for the initial development of nicotine dependence.

Suresh Kumar, Vigneswaran, Divya Merciline and Aparna Priyamvada (2013) demonstrated that smokers scored highest for novelty seeking, reward dependence and persistence, and lower on harm avoidance, than non-smokers did, in Cloninger's psychobiological model of personality dimensions (see also Etter, 2010). Rezwanfard, Ekhtiari, Mokri, Djavid and Kaviani (2010) and Bloom, Matsko and Cimino (2014) detected a significant positive relationship between impulsivity and cigarette smoking. Other studies revealed a strong association between smoking and mental disorders, such as schizophrenia, depression and anxiety (Holma, Holma, Melartin, Ketokivi, \& Isometsä, 2013; Lyvers, Carlopio, Bothma, \& Edwards, 2013; Rondina, Gorayeb, \& Botelho, 2007; Singh, Singh, \& Singh, 2011; Talati et al., 2013). McChargue et al. (2011) hypothesised that a high level of impulsivity, as a trait, may moderate the relationship between rumination and the number of major depressive episodes among cigarette smokers.

Few studies have examined the association between affective temperaments and smoking in adults.

The five affective temperament types (depressive, cyclothymic, hyperthymic, irritable and anxious) play a definitive role in determining a predisposition to affective disorders (Akiskal \& Akiskal, 2005; DeGeorge, Walsh, Barrantes-Vidal, \& Kwapil, 2014). Akiskal's affective temperaments overlap with the Five Factor model of personality (Blöink, Briegera, Akiskal, \& Marneros, 2005; Kwapil et al., 2013) and with Cloninger's model (Cloninger, 2000; Harnic et al., 2013; Ristić-Ignjatović et al., 2014; Rózsa et al., 2008).

The concept of affective temperaments is clinically useful in mood disorders and in patients with rheumatoid arthritis (Rezvani et al., 2014), obesity (Amann et al., 2009), HIV (Pompili et al., 2013) and alcohol and/or opiate dependence (Khazaal et al., 2013). Bisol, Soldado, Albuquerque, Lorenzi and Lara (2010) found that smoking was more frequent in people with cyclothymic and irritable temperaments and less frequent in people with depressive and hyperthymic temperaments. Anxious temperament was not associated with being a smoker.

Cigarette smoking is a prevalent addiction among individuals with bipolar disorder (Heffner, Strawn, DelBello, Strakowski, \& Anthenelli, 2011), who are often characterised by cyclothymic temperament (Rovai et al., 2013). As irritable temperament is associated with impulsiveness, it may be considered a risk factor for smoking. Eory et al. (2015) demonstrated that an irritable temperament in adult primary care patients was a predictor of smoking initiation in females, whereas a depressive temperament predicted smoking maintenance in males. Mombach, de Souza Brito, Padoin, Casagrande and Mottin (2016) reported an association between nicotine-dependent bariatric surgery candidates and anxious temperaments.

The aim of our cross-sectional study was to explore the differences between self-declared nicotine-dependent and non-nicotine-dependent individuals in affective temperaments, as assessed with the Temperament Evaluation of Memphis, Pisa, Paris and San DiegoAutoquestionnaire (TEMPS-A) in a Polish non-clinical population. We were interested only in people who subjectively considered themselves addicted or not addicted to nicotine. Because there may have been differences in affective temperaments between males and females, we also took gender differences into account. In contrast to many other studies, our study was conducted among nonclinical participants representing the general adult male and female population.

Based on the data from other studies, we expected that high levels of unstable, externalised affective temperaments (cyclothymic and irritable) would be observed in nicotine-dependent individuals when compared to non-nicotine-dependent individuals, regardless of sex.

\section{PARTICIPANTS AND PROCEDURE}

\section{PARTICIPANTS}

The sample consisted of 678 healthy Caucasian adults (441 females and 237 males) recruited from a non-clinical population. Participants were aged between 17 and 69 years $(M=30.72$ years, $S D=9.66$ years). The study was part of a large research project 
into personality. Participants were recruited directly by the psychologists, who contacted students of various faculties, their colleagues, friends, parents and, in the case of working students, their co-workers. All participants were asked whether they had any addictions, and those who declared nicotine dependence were classified as such. Participants were not asked how many cigarettes they typically smoked. Those who indicated any other addiction were excluded from the analysis. The subgroup of self-declared nicotine-dependent individuals comprised 134 subjects, including 89 females and 45 males. The non-nicotine dependent subgroup consisted of 544 subjects, including 352 females and 192 males. Table 1 shows the demographic characteristics of both groups.

The study was anonymous, and participation was voluntary. Informed consent was obtained from all participants before they joined the study, and the participants did not receive compensation. The research project was accepted by the local Ethics Commission at the Faculty of Psychology, University of Warsaw.

Table 1 shows that females outnumbered males nearly twofold in both groups.

The groups were not symmetrical in educational level $\left[\chi^{2}(2)=36.31, p<.001\right]$.

\section{MEASURES}

We used the Polish version of the TEMPS-A to assess affective temperaments (Borkowska et al., 2010). TEMPS-A is a self-reporting instrument comprising 110 items (109 for males) with a yes/no response format (Akiskal, Akiskal, Haykal, Manning, \& Connor, 2005; Dembińska-Krajewska \& Rybakowski, 2014). TEMPS-A comprises five scales (Cronbach's $\alpha$ for the Polish version are given in parentheses): depressive $(\alpha=.70)$, cyclothymic $(\alpha=.77)$, hyperthymic $(\alpha=.75)$, irritable $(\alpha=.76)$ and anxious $(\alpha=.83)$. The score for each scale was calculated using the mathematical equation: the sum of the score of the variables in each category divided by the number of variables (21 for each of the first four categories of temperaments, and 26 for the last category).

\section{STATISTICAL ANALYSIS}

The statistical analysis was performed using SPSS Statistics version 22.0 (IBM Corp., 2013). We have reported descriptive statistics, such as the means and standard deviations of the main variables. Since the compared groups were not equinumerous, the Mann-Whitney $U$ test was used to verify the significance of differences between the nicotine-dependent and non-nicotine-dependent individuals, as well as between males and females in both groups.

\section{RESULTS}

The mean results and standard deviations for affective temperaments for the nicotine-dependent and non-nicotine-dependent groups are shown in Table 2.

As shown in Table 2, cyclothymic, irritable and anxious temperaments were more prevalent in nicotine-dependent individuals than in non-nicotine-dependent subjects. No significant differences between depressive and hyperthymic temperaments were found among the two groups.

Table 3 compares the basic descriptive statistics for males and females in both groups.

As the data in Table 3 show, the number of individuals with anxious temperaments was higher among nicotine-dependent females than it was among males. No significant differences were found for the other affective temperaments between the males and females.

Among the non-nicotine-dependent individuals, more depressive, cyclothymic and anxious temperaments were found in females than in males, and more hyperthymic temperaments were observed in males than in females. No significant gender difference was found in irritable temperament in this group.

\section{DISCUSSION}

This study focused on affective temperaments in nicotine-dependent and non-nicotine-dependent in-

Table 1

Demographic characteristics of nicotine-dependent and non-nicotine-dependent individuals

\begin{tabular}{lcc} 
& Nicotine-dependent $(n=134)$ & Non-nicotine-dependent $(n=544)$ \\
\hline Gender $(\mathrm{M} / \mathrm{F})$ & $45 / 89$ & $192 / 352$ \\
Age $(M \pm S D)$ & $30.45 \pm 9.22$ & $30.78 \pm 9.77$ \\
Educational level ${ }^{*}:$ & 355 \\
High & 52 & 160 \\
Secondary & 77 & 17 \\
Primary & 5 &
\end{tabular}


Table 2

Mean and standard deviation comparisons for affective temperaments in the nicotine-dependent and non-nicotine-dependent groups

\begin{tabular}{|c|c|c|c|c|}
\hline Temperament & $\begin{array}{c}\text { ND }(n=134) \\
M(S D)\end{array}$ & $\begin{array}{c}\text { NND }(n=544) \\
M(S D)\end{array}$ & $Z$ & Cohen's $d$ \\
\hline Depressive & $0.35(0.17)$ & $0.34(0.16)$ & -0.68 & 0.06 \\
\hline Cyclothymic & $0.42(0.22)$ & $0.32(0.21)$ & $-5.00^{* * *}$ & 0.46 \\
\hline Hyperthymic & $0.51(0.21)$ & $0.50(0.20)$ & -0.68 & 0.05 \\
\hline Irritable & $0.28(0.21)$ & $0.20(0.17)$ & $-4.76^{* * *}$ & 0.42 \\
\hline Anxious & $0.32(0.22)$ & $0.28(0.20)$ & $-1.96^{*}$ & 0.19 \\
\hline
\end{tabular}

Note. ND - nicotine-dependent, NND - non-nicotine-dependent, $Z$ - value for the Mann-Whitney $U$-test, ${ }^{* * *} p<.001,{ }^{*} p<.05$.

Table 3

Mean and standard deviation comparisons for affective temperament traits in males and females in nicotinedependent and non-nicotine-dependent groups

\begin{tabular}{|c|c|c|c|c|}
\hline Temperament & $\begin{array}{c}\text { Males } \\
(n=45 \mathrm{ND} ; n=192 \mathrm{NND}) \\
M(S D)\end{array}$ & $\begin{array}{c}\text { Females } \\
(n=89 \mathrm{ND} ; n=352 \mathrm{NND}) \\
M(S D)\end{array}$ & $Z$ & Cohen's $d$ \\
\hline \multicolumn{5}{|l|}{ Depressive } \\
\hline ND & $0.33(0.16)$ & $0.37(0.17)$ & -1.29 & -0.24 \\
\hline NND & $0.30(0.15)$ & $0.36(0.16)$ & $-4.48^{* * *}$ & -0.39 \\
\hline \multicolumn{5}{|l|}{ Cyclothymic } \\
\hline ND & $0.39(0.22)$ & $0.44(0.22)$ & -1.43 & -0.23 \\
\hline NND & $0.29(0.21)$ & $0.33(0.20)$ & $-2.32^{*}$ & -0.19 \\
\hline \multicolumn{5}{|l|}{ Hyperthymic } \\
\hline ND & $0.55(0.20)$ & $0.49(0.21)$ & -1.61 & 0.29 \\
\hline NND & $0.52(0.20)$ & $0.48(0.20)$ & $-2.43^{*}$ & 0.20 \\
\hline \multicolumn{5}{|l|}{ Irritable } \\
\hline ND & $0.27(0.24)$ & $0.29(0.19)$ & -0.84 & -0.09 \\
\hline NND & $0.21(0.18)$ & $0.19(0.17)$ & -1.47 & 0.11 \\
\hline \multicolumn{5}{|l|}{ Anxious } \\
\hline ND & $0.24(0.19)$ & $0.37(0.22)$ & $-3.37^{* * *}$ & -0.63 \\
\hline NND & $0.20(0.16)$ & $0.31(0.21)$ & $-6.34^{* * *}$ & -0.59 \\
\hline
\end{tabular}

Note. ND - nicotine-dependent, NND - non-nicotine-dependent, $Z$ - value for the Mann-Whitney $U$-test; *** $p<.001 ;{ }^{*} p<.05$.

dividuals. The results supported the hypothesis that nicotine-dependent individuals would score higher for cyclothymic and irritable temperaments than non-nicotine-dependent individuals would, in agreement with Bisol et al. (2010). As demonstrated by Walsh, Brown, Barrantes-Vidal and Kwapil (2013), cyclothymic and irritable temperaments may have the most maladaptive consequences in daily life, ranging from a high positive correlation with negative affect and elevated stress reactivity to engagement in risky behaviours. Unseld et al. (2012) showed that cyclothy- mic and highly irritable temperaments serve as predictors of self-reported nicotine dependence in young adults.

According to Rovai et al. (2013), cyclothymic temperament includes rapid fluctuations in mood and emotional instability, while irritable temperament includes difficulties in interpersonal relationships. Both temperaments are related to mood, anxiety and substance use disorders. Caldirola et al. (2013) showed that nicotine use may enhance cognitive functioning (verbal memory and working memory) 
in patients with mood disorders, suggesting that smoking may be a form of cognitive self-medication that mediates the association between smoking and mood disorders.

A somewhat surprising result of our study was that anxious temperaments were more prevalent in nicotine-dependent individuals than non-nicotine-dependents. However, the result was not statistically significant. The association between anxiety and smoking is complex. As suggested by Etter, Pélissolo, Pomerleau and De Saint-Hilare (2003), high levels of Cloninger's harm avoidance (equivalent to anxious temperament) could predict smoking in people who seek the anxiolytic effects of smoking. Smokers often report that cigarettes alleviate feelings of stress; however, tobacco use does not reduce stress and may even increase stress (Parrot, 1999; see also Kassel, Stroud, \& Paronis, 2003; Moylan, Jacka, Pasco, \& Berk, 2012). Nevertheless, Moylan et al. (2013) showed that cigarette smoking may influence symptoms of anxiety and anxiety disorders through complex biological mechanisms, including neurotransmitters.

With regard to gender differences in affective temperaments, the results obtained from the non-nicotine-dependent group were in line with the tendencies of the general population. The females exhibited more depressive, cyclothymic and anxious temperaments than the males did, whereas the males exhibited more hyperthymic temperaments than the females did. No significant difference was found between the genders for irritable temperament (see also Blöink et al., 2005; Borkowska et al., 2010; Oniszczenko, Stanisławiak, Dembińska-Krajewska, \& Rybakowski, 2016; Vázquez, Tondo, Mazzarini, \& Gonda, 2012).

In the nicotine-dependent group, only the anxious temperament trait differed between females and males; females scored higher than males did on the anxious temperament scale. No significant difference was found with regard to the other affective temperaments between males and females in the nicotine-dependent group. This result was inconsistent with other studies which demonstrated that, in the general population, anxious temperaments are not associated with being a smoker (Bisol et al., 2010; Unseld et al., 2012). By contrast, Castro, Oliveira, Araujo and Pedroso (2008) claimed that females with severe nicotine dependence have more symptoms of anxiety and depression, while only heavy male smokers showed higher levels of anxiety. Our result suggests that an anxious temperament may be a significant predictor of nicotine dependence in females. Women, being more anxious than men, may be highly motivated to smoke in response to anxiety-related distress as a way of coping with such affective disturbances (see Zvolensky, Schmidt, \& Stewart, 2003).

This study has limitations. Our nicotine-dependence assessment was based solely on self-reports, and no additional tests were performed. Participants were not asked about the number of cigarettes they typically smoked. We did not control for the mental health status of participants, and females were over-represented in the study group. The nicotine-dependent and non-nicotine-dependent groups were not symmetrical in terms of educational level, and the cross-sectional design of the study limits causal interpretations.

\section{CONCLUSIONS}

Our results support the hypothesis that affective, cyclothymic and irritable temperaments in both genders and anxious temperaments in females are predictors of nicotine dependence in adults in the general population. The assessment of these temperament traits may be useful for clinical psychologists and psychiatrists to help smokers decide to stop smoking.

\section{ACKNOWLEDGMENTS}

This research was supported by a grant from the University of Warsaw (BST 1777012016).

\section{ReferenCES}

Akiskal, K. K., \& Akiskal H. S. (2005). The theoretical underpinnings of affective temperaments: Implications for evolutionary foundations of bipolar disorder and human nature. Journal of Affective Disorders, 85, 231-239. doi: 10.1016/j. jad.2004.08.002

Akiskal, H. S., Akiskal, K. K., Haykal, R. F., Manning, J. S., \& Connor, P. D. (2005). TEMPS-A: Progress towards validation of a self-rated clinical version of the temperament evaluation of the Memphis, Pisa, Paris, and San Diego autoquestionnaire. Journal of Affective Disorders, 85, 3-16. doi: 10.1016/j.jad.2004.12.001

Amann, B., Mergl, R., Torrent, C., Perugi, G., Padberg, F., El-Gjamal, N., \& Laakmann, G. (2009). Abnormal temperament in patients with morbid obesity seeking surgical treatment. Journal of Affective Disorders, 118, 155-160. doi: 10.1016/j. jad.2009.01.020

Bisol, L.W., Soldado, F., Albuquerque, C., Lorenzi, T. M., \& Lara, D. R. (2010). Emotional and affective temperaments and cigarette smoking in a large sample. Journal of Affective Disorders, 127, 89-95. doi: 10.1016/j.jad.2010.04.016

Bloom, E. L., Matsko, S. V., \& Cimino, C. R. (2014). The relationship between cigarette smoking and impulsivity: A review of personality, behavioral, and neurobiological assessment. Addiction Research \& The ory, 22, 386-397. doi: 10.3109/16066359.2013.867432 
Blöink, R., Briegera, P., Akiskal, H. S., \& Marneros, A. (2005). Factorial structure and internal consistency of the German TEMPS-A scale: Validation against the NEO-FFI questionnaire. Journal of Affective Disorders, 85, 77-83. doi: 10.1016/S01650327(03)00101-0

Borkowska, A., Rybakowski, J. K., Drożdż, W., Bieliński, M., Kosmowska, M., Rajewska-Rager, A., ..., \& Akiskal, H. S. (2010). Polish validation of the TEMPS-A: The profile of affective temperaments in a college student population. Journal of Affective Disorders, 123, 36-41. doi: 10.1016/j. jad.2009.09.024

Caldirola, D., Daccò, S., Grassi, M., Citterio, A., Menotti, R., Cavedini, P., ..., \& Perna, G. (2013). Effects of cigarette smoking on neuropsychological performance in mood disorders: A comparison between smoking and nonsmoking inpatients. Journal of Clinical Psychiatry, 74, e130-136. doi: 10.4088/JCP.12m07985

Castro, M., Oliveira, M. S., Araujo, R. B., \& Pedroso, R. S. (2008). Relationship between gender and depressive and anxiety symptoms in smokers. $R e$ vista de Psiquiatria do Rio Grande do Sul, 30, 25-30. doi: 10.1590/S0101-81082008000100008

Cheng, H., \& Furnham, A. (2016). The Big-Five personality traits, maternal smoking during pregnancy, and educational qualifications as predictors of tobacco use in a nationally representative sample. PLoS One, 11, e0145552. doi: 10.1371/journal.pone.0145552

Cloninger, C. R. (2000). Biology of personality dimensions. Current Opinion in Psychiatry, 13, 611-616. doi: 10.1097/00001504-200011000-00024

DeGeorge, D. P., Walsh, M. A., Barrantes-Vidal, N., \& Kwapil, T. R. (2014). A three-year longitudinal study of affective temperaments and risk for psychopathology. Journal of Affective Disorders, 164, 94-100. doi: 10.1016/j.jad.2014.04.006

Dembińska-Krajewska, D., \& Rybakowski, J. (2014). The temperament evaluation of Memphis, Pisa and San Diego autoquestionnaire (TEMPS-A): An important tool to study affective temperaments. Psychiatria Polska, 48, 261-276.

Eory, A., Rozsa, S., Gonda, X., Dome, P., Torzsa, P., Simavorian, T., ..., \& Kalabay, L. (2015). The association of affective temperaments with smoking initiation and maintenance in adult primary care patients. Journal of Affective Disorders, 172, 397402. doi: 10.1016/j.jad.2014.10.036

Etter, J. F. (2010). Smoking and Cloninger's Temperament and Character Inventory. Nicotine \& Tobacco Research, 12, 919-926. doi: 10.1093/ntr/ntq116

Etter, J. F., Pélissolo, A., Pomerleau, C. S., \& De Saint-Hilare, Z. (2003). Associations between smoking and heritable temperaments traits. Nicotine \& Tobacco Research, 5, 401-409. doi: $10.1080 / 1462220031000094240$
Hakulinen, C., Hintsanen, M., Munafò, M. R., Virtanen, M., Kivimäki, M., Batty, G. D., \& Jokela, M. (2015). Personality and smoking: Individual-participant meta-analysis of nine cohort studies. $A d-$ diction, 110, 1844-1852. doi: 10.1111/add.13079

Harnic, D., Pompili, M., Mazza, M., Innamorati, M., Di Nicola, M., Catalano, V., ..., \& Janiri, L. (2013). Affective temperaments and psychopathological dimensions of personality in bipolar and cyclothymic patients. Behavioral Medicine, 39, 17-23. doi: 10.1080/08964289.2012.713043

Heffner, J. L., Strawn, J. R., DelBello, M. P., Strakowski, S. M., \& Anthenelli, R. M. (2011). The co-occurrence of cigarette smoking and bipolar disorder: phenomenology and treatment considerations. Bipolar Disorders, 13, 439-453. doi: 10.1111/j.13995618.2011.00943.x

Holma, I. A. K., Holma, K. M., Melartin, T. K., Ketokivi, M., \& Isometsä, E. T. (2013). Depression and smoking: A 5-year prospective study of patients with major depressive disorder. Depression and Anxiety, 30, 580-588. doi: 10.1002/da.22108

IBM Corp. (2013). IBM SPSS Statistics for Windows, Version 22.0. Armonk, NY: IBM Corp.

Kassel, J. D., Stroud, L. R, \& Paronis, C. A. (2003). Smoking, stress, and negative affect: Correlation, causation, and context across stages of smoking. Psychological Bulletin, 129, 270-304. doi: 10.1037/0033-2909.129.2.270

Khazaal, Y., Gex-Fabry, M., Nallet, A., Weber, B., Favre, S., Voide, R., ..., \& Aubry, J. M. (2013). Affective temperaments in alcohol and opiate addictions. Psychiatric Quarterly, 84, 429-438. doi: 10.1007/ s11126-013-9257-3

Kleinjan, M., Vitaro, F., Wanner, B., Brug, J., van den Eijnden, R. J. J. M., \& Engels, R. C. M. (2012). Predicting nicotine dependence profiles among adolescent smokers: The roles of personal and social-environmental factors in a longitudinal framework. BMC Public Health, 12, 196. doi: 10.1186/1471-2458-12-196

Kwapil, T. R., DeGeorge, D., Walsh, M. A., Burgin, C. J., Silvia, P. J., \& Barrantes-Vidal, N. (2013). Affective temperaments: Unique constructs or dimensions of normal personality by another name? Journal of Affective Disorders, 151, 882-890. doi: 10.1016/j. jad.2013.07.028

Lyvers, M., Carlopio, C., Bothma, V., \& Edwards, M. S. (2013). Mood, mood regulation expectancies and frontal systems functioning in current smokers versus never-smokers in China and Australia. Addictive Behaviors, 38, 2741-2750. doi: 10.1016/j. addbeh.2013.07.002

McChargue, D. E., Cohen, L. M., \& Werth-Cook, J. (2004). The influence of personality and affect on nicotine dependence among male college students. Nicotine \& Tobacco Research, 6, 287-294. doi: 10.1080/14622200410001676323 
McChargue, D. E., Drevo, S., Herrera, M. J., Doran, N., Salvi, S., \& Klanecky, A. K. (2011). Trait-impulsivity moderates the relationship between rumination and number of major depressive episodes among cigarette smokers. Mental Health and Substance Use, 4, 96-104. doi: 10.1080/17523281.2011.554326

Mombach, K. D., de Souza Brito, C. L., Padoin, A. V., Casagrande, D. S., \& Mottin, C. C. (2016). Emotional and affective temperaments in smoking candidates for bariatric surgery. PLoS One, 11, e0150722. doi: 10.1371/journal.pone.0150722

Moylan, S., Jacka, F. N., Pasco, J. A., \& Berk, M. (2012). Cigarette smoking, nicotine dependence and anxiety disorders: A systematic review of population-based, epidemiological studies. BMC Medicine, 10, 123. doi: 10.1186/1741-7015-10-123

Moylan, S., Jacka, F. N., Pasco, J. A., \& Berk, M. (2013). How cigarette smoking may increase the risk of anxiety symptoms and anxiety disorders: A critical review of biological pathways. Brain and Behavior, 3, 302-326. doi: 10.1002/brb3.137

Munafó, M. R., Zetteler, J. I., \& Clark, T. G. (2007). Personality and smoking status: A meta-analysis. Nicotine \& Tobacco Research, 9, 405-413. doi: 10.1080/14622200701188851

Oniszczenko, W., Stanisławiak, E., Dembińska-Krajewska, D., \& Rybakowski, J. K. (2016). Regulative theory of temperament versus affective temperaments measured by the temperament evaluation of Memphis, Pisa, Paris and San Diego auto-questionnaire (TEMPS-A): A study in a non-clinical Polish sample. Manuscript submitted for publication.

Parrot, A. C. (1999). Does cigarette smoking cause stress? American Psychologist, 54, 817-820.

Pompili, M., Pennica, A., Serafini, G., Battuello, M., Innamorati, M., Teti, E., ..., \& Girardi, P. (2013). Depression and affective temperaments are associated with poor health-related quality of life in patients with HIV infection. Journal of Psychiatric Practice, 19, 109-117. doi: 10.1097/01. pra.0000428557.56211

Rezvani, A., Aytüre, L., Arslan, M., Kurt, E., EroğluDemir, S., \& Karacan, İ. (2014). Affective temperaments in patients with rheumatoid arthritis. International Journal of Rheumatic Diseases, 17, 34-38. doi: 10.1111/1756-185X.12033

Rezwanfard, M., Ekhtiari, H., Mokri, A., Djavid, G. E., \& Kaviani, H. (2010). Psychological and behavioral traits in smokers and their relationship with nicotine dependence level. Archives of Iranian Medicine, 13, 395-404. doi: 010135/AIM.006

Ristić-Ignjatović, D., Hinić, D., Bessonov, D., Akiskal, H. S., Akiskal, K. K., \& Ristić, B. (2014). Towards validation of the short TEMPS-A in non-clinical adult population in Serbia. Journal of Affective Disorders, 164, 43-49. doi: 10.1016/j.jad.2014.04.005

Rondina, R. C., Gorayeb, R., \& Botelho, C. (2007). Psychological characteristics associated with tobacco smoking behavior. Journal Brasileiro de Pneumologia, 33, 592-601. doi: 10.1590/S180637132007000500016

Rovai, L., Maremmani, A. G., Rugani, F., Bacciardi, S., Pacini, M., Dell'Osso, L., ..., \& Maremmani, I. (2013). Do Akiskal \& Mallya's affective temperaments belong to the domain of pathology or to that of normality? European Review for Medical and Pharmacological Science, 17, 2065-2079.

Rózsa, S., Rihmer, Z., Gonda, X., Szili, I., Rihmer, A., Kő, N., ..., \& Akiskal, H. S. (2008). A study of affective temperaments in Hungary: Internal consistency and concurrent validity of the TEMPS-A against the TCI and NEO-PI-R. Journal of Affective Disorders, 106, 45-53. doi: 10.1016/j. jad.2007.03.016

Singh, A., Singh, S. K., \& Singh, R. K. (2011). Pathological personality and approval motive in smokers. Journal of Projective Psychology \& Mental Health, 18, 168-172.

Suresh Kumar, M., Vigneswaran, K., Divya Merciline, A., \& Aparna Priyamvada, M. R. (2013). Personality correlates of BIS and BAS in tobacco dependents. International Journal of Scientific Research, 2, 342-344.

Talati, A., Wickramaratne, P. J., Keyes, K. M., Hasin, D. S., Levin, F. R., \& Weissman, M. M. (2013). Smoking and psychopathology increasingly associated in recent birth cohorts. Drug and Alcohol Dependence, 133, 724-732. doi: 10.1016/j.drugalcdep.2013.08.025

Unseld, M., Dworschak, G., Tran, U. S., Plener, P. L., Erfurth, A., Walter, H., ..., \& Kapusta, N. D. (2012). The concept of temperament in psychoactive substance use among college students. Journal of Affective Disorders, 141, 324-330. doi: 10.1016/j. jad.2012.03.028

Vázquez, G. H., Tondo, L., Mazzarini, L., \& Gonda, X. (2012). Affective temperaments in general population: $\mathrm{A}$ review and combined analysis from national studies. Journal of Affective Disorders, 139, 18-22. doi: 10.1016/j.jad.2011.06.032

Walsh, M. A., Brown, L. H., Barrantes-Vidal, N., \& Kwapil, T. R. (2013). The expression of affective temperaments in daily life. Journal of Affective Disorders, 145, 179-186. doi: 10.1016/j.jad.2012.07.026

Zvolensky, M. J., Schmidt, N. B., \& Stewart, S. H. (2003). Panic disorder and smoking. Clinical Psychology: Science and Practice, 10, 29-51. doi: 10.1093/clipsy.10.1.29 